\title{
ZİRKONYA VE VENEER SERAMİK ARASINDAKİ BAĞLANTIYA FARKLI FIRINLAMA UYGULAMALARININ ETKİSI ${ }^{*}$
}

\section{THE EFFECT OF DIFFERENT FURNACE APPLICATIONS ON THE CONNECTION BETWEEN ZIRCONIA AND VENEER CERAMIC ${ }^{*}$}

\author{
Dr. Öğr. Üyesi Türker AKAR ${ }^{*} \quad$ Prof. Dr. Hakan DEMİR**
}

Makale Kodu/Article code: 4221

Makale Gönderilme tarihi; 21.11 .2019

Türker Akar: ORCID ID: 0000-0003-2035-8686

Kabul Tarihi: 28.05.2020

Hakan Demir: ORCID ID: 0000-0002-1769-1667

DOI : $10.17567 /$ ataunidfd. 743910

öz

Amaç: Çalışmamızın amacı, hem zirkonyum oksit esaslı alt yapı blokların sinterlenmesi, hem de alt yapı üzerine uygulanacak olan veneer seramiklerin fırınlanması esnasında, özellikle soğuma hızları dikkate alındığında, farklı fırınlama program tercihlerinin, zirkonyum oksit ve veneer seramik arasındaki bağlantıya etkisini araştırmaktır.

Gereç ve Yöntem: 144 adet Y-TZP alt yapı $(7 \mathrm{~mm}$ ** $3 \mathrm{~mm}$.) olacak şekilde üretilmiştir. Daha sonra bu örnekler sinterleme işleminden sonraki soğutulma prosedürlerine göre 2 ana gruba ayrılmıştır (grup P1-n=72 ve grup P5-n=72). Bu iki ana grup ise iki farklı marka porselenin üretici firma tavsiyeli yavaş soğutma ve bizim belirlediğimiz hızlı soğutma olmak üzere 4 er adet alt gruplara ayrııışır. Üretilen örneklerin hepsine 5000 devir termal siklus uygulanmışır. Her bir örnek Universal test cihazında 0,5mm/dak. kafa hızında makaslama bağlanma dayanımı testine tabi tutulmuştur. Kesme işlemini yapacak bıçak ucu, $1 \mathrm{~mm}$. kalınlığında ve künt olacak şekilde hazırlanmıştır. Test bıçak ucu ile örnekler arasındaki açı $90^{\circ}$, hızı ise $1 \mathrm{~mm} /$ dakika olarak gerçekleştirilmiştir. İstatistiksel analizler Mann Whitney $U$ testi kullanılarak sonuçları $p<0.05$ anlamllık düzeyine göre değerlendirilmiştir.

Bulgular: Bütün veriler dikkate alındığında elde edilen en yüksek makaslama bağlanma dayanımı değeri $(25,57 \pm 0,64 \mathrm{MPa})$, P5 sinterleme programında hazırlanan zirkonyum oksit alt yapılara yavaş soğuma işlemiyle uygulanmış Vita VM9 veneer porselen grubunda termal siklus işlemi öncesi elde edilmiştir. En düşük makaslama bağlanma değeri $(19,75 \pm 0,80 \mathrm{MPa})$ ise $\mathrm{P} 1$ sinterleme programında hazırlanan zirkonyum oksit alt yapılara hızlı soğuma işlemi ile uygulanmış Noritake CZR veneer porselen grubunda termal siklus ișlemi sonrası elde edilmiștir.

Sonuç: Sonuç olarak P1 (Hızlı) ve P5 (Yavaş) olmak üzere sinterlenen zirkonyum oksit alt yapıların bağlanma değerleri karşılaştııılığında P5 ana grubundaki bağlanma dayanımı değerleri, P1 grubundakilere göre daha yüksek bulunmuştur.

Anahtar Kelimeler: Zirkonyum oksit, bağlanma dayanımı, veneer seramik.

\section{ABSTRACT}

Aim: The aim of this study is to investigate the effect of different firing program preferences on the connection between zirconium oxide and veneer ceramics both during sintering of zirconium oxide based substructure blocks and during the firing of veneer ceramics to be applied on the substructure, especially considering the cooling rates.

Materials and Methods: 144 Y-TZP substructures $(7 \mathrm{~mm} . * 3 \mathrm{~mm}$.) were produced. These samples were then divided into 2 main groups (group P1-n = 72 and group P5-n = 72) according to cooling procedures after sintering. These two main groups are divided into 4 subgroups as slow cooling and fast cooling determined by the manufacturer of two different brands of porcelain. All of the samples were subjected to 5000 cycles of thermal cycling. Each sample was tested with a Universal tester of $0.5 \mathrm{~mm}$./min. shear bond strength test at head speed. Blade tip for cutting, $1 \mathrm{~mm}$. thick and blunt. The angle between the test blade and the specimens was $90^{\circ}$ and the speed was $1 \mathrm{~mm} /$ minute. Mann Whitney $\mathrm{U}$ test was used for statistical analysis and the results were evaluated according to $p<0.05$ significance level.

Results: When all the data were taken into consideration, the highest shear bond strength value $(25,57 \pm 0,64 \mathrm{MPa})$ was obtained before the thermal cycle in Vita VM9 veneer porcelain group which was applied to the zirconium substructures prepared by P5 sintering program by slow cooling process. The lowest shear bonding value $(19,75 \pm 0,80 \mathrm{MPa})$ was obtained by fast cooling process to the zirconium substructures prepared in P1 sintering program after Noritake CZR veneer porcelain group after thermal cycling process.

Conclusion: As a result, when the binding values of sintered zirconium oxide substructures, P1 (Fast) and P5 (Slow) were compared, the bond strength values in the P5 main group were higher than those in the P1 group.

Key Words: Zirconium, bond strength, veneer ceramic.

\footnotetext{
**Erzincan Binali Yıldırım Üniversitesi Diş Hekimliği Fakültesi Protetik Diş Tedavisi A.D.

**Cumhuriyet Üniversitesi Diş Hekimliği Fakültesi Protetik Diş Tedavisi A.D.

${ }^{\ddagger}$ Bu çalışma Cumhuriyet Üniversitesi Bilimsel Araştırma Projeleri (CÜBAP) tarafından Diş-121 proje numarası ile desteklenmiş olup $03|01| 2014$ tarihinde Cumhurivet Üniversitesi Dishekimliăi Fakültesi'nde doktora tezi olarak sunulmustur.

Kaynakça Bilgisi Akar T, Demir H. Zirkonya ve veneer seramik arasındaki bağlantıya farklı fırınlama uygulamalarının etkisi. Atatürk Üniv Diş Hek Fak Derg 2020; 30: 626-32.

Citation Information: Akar T, Demir H. The Effect of different furnace applications on the connection between zirconia and veneer ceramic. J Dent Fac Atatürk Uni 2020; 30: 626-32.
} 


\section{GİRİş}

Seramiklerin diş hekimliğinde kullanımı ise Fransız eczaci Alexis Duchateau tarafından 1774 'de gerçekleştirilmiştir. Ardından 1778'de Fransız diş hekimi Dubois de Chemant ilk mineral bazlı seramik dişlerini üretmiştir. ${ }^{1}$ Seramik malzemelerin sabit restorasyonlarda kullanımı 19 . yüzyılın sonuna gelindiğinde önem kazanmaya başlamıştır. ${ }^{2}$ McLean, 1963 yılında alüminöz seramikleri geliştirerek tam seramik sistemlerin temelini oluşturmuşlardır. ${ }^{3}$ Alüminöz seramikler, 20-30 $\mu \mathrm{m}$ boyutlarında alümina kristallerinin \%40-50 oranında yapıya eklenmesi ile elde edilmiştir. ${ }^{4} \mathrm{Bu}$ işlem seramiğin mekanik olarak daha güçlü ve termal şoklara daha dirençli bir yapıya dönüşmesini sağlamış, böylece feldspatik seramiklerin eğme mukavemetleri ortalama 65MPa iken, alüminöz seramiklerinki 131MPa olmuştur.5,6

Yttrium oksit, saf zirkonyayı oda sıcaklığında stabilize etmek ve multifazı parsiyel stabilize zirkonyayı elde etmek amac ile yapıya ilave edilen stabilize edici bir oksittir. ${ }^{4}$ Oda sıcaklığında tetragonal fazdaki zirkonya ve stabilize edici oksit olarak \% 2-3'lük $\mathrm{Y}_{2} \mathrm{O}_{3}$ içerir. ${ }^{7}$ Zirkonyayı oda sıcaklığında t-fazında sabitleyen faktörleri; işlem sıcaklığı, $\mathrm{Y}_{2} \mathrm{O}_{3}$ içeriği ve tanecik boyutu olarak sayabiliriz.. Ayrıca materyalin mekanik özellikleri de bu parametrelere bağlıdır. Kendiliğinden oluşan $\mathrm{t} \rightarrow \mathrm{m}$ faz dönüşümünün gerçekleşebilmesi için, $\mathrm{Y}_{2} \mathrm{O}_{3}$ konsantrasyonuna bağlı olarak var olan kritik bir tanecik boyutu vardır ve faz dönüşümü bu tanecik boyutunun üzerindeyken gerçekleşir. Bu dönüşüm, çok küçük tanecikli yapıda inhibe olmaktadır. ${ }^{8}$

Y-TZP nin mekanik özelliklerini etkileyen faktörler şu şekilde belirtilmiştir:

1. Stabilize edici oksidin miktarı

2. Zirkonya partikül büyüklüğü ve şekli

3. Sıcaklık

4. Nem

5. Zaman. $^{9}$

Tek tek inceleyecek olursak stabilizatör oksitin gren büyüklüğünün ve oranının artması faz değişimini hızlandıran bir faktördür. Çeşitli çalışmalarla elde edilen bilgilere göre en iyi mekanik özelliklerin, yapının içerisine \%2 oranında $\mathrm{Y}_{2} \mathrm{O}_{3}$ ilave edilmesi ile elde edildiği belirlenmiştir. Sinterlemenin düşük ısıda yapılması ise yapı içindeki porözite miktarını artırarak kırıma dayanıklıı̆ında azalmaya neden olduğu belirtilmiştir. ${ }^{5,10,11}$ Zirkonya partiküllerinin şekli ve boyutu da mekanik özellikleri etkilemektedir. İdeal kırılma dayanıklılı̆ı için, materyalin partikül büyüklüğünün 0,3 um olması gerektiği bildirilmiştir. Stabilizatör miktarının
\%1 oranında arttırılması, yani \% $3 \mathrm{Y}_{2} \mathrm{O}_{3}$ ilave edilmesi, partikül boyutunun $1 \mu \mathrm{m}$ 'a ulaşmasına ve malzemenin mekanik özelliklerinin bozulmasına neden olur. ${ }^{12,13}$ Sıcaklık artışı Y-TZP' nin, tetragonal fazdan monoklinik faza spontan geçiş olması sebebiyle ve malzemenin yarı-stabil özelliğini kaybetmesinden dolayı olumsuz etkilemektedir. Bu faz değişiminin ortaya çıkması için 200-300 ${ }^{0} \mathrm{C}^{\prime}$ lik kritik bir ISı aralığı gerekmektedir. Malzemenin $100-400{ }^{\circ} \mathrm{C}^{\prime}$ de uzun süre tutulması sonucu ortaya çıkan faz değişimine 'low-temperature degradation' denir. Ortamda nemin de var olması durumunda faz değişim miktarı artacak ve materyalin yarı stabil özelliğini kaybetmesinden dolayı mekanik özellikleri bozulacaktır. ${ }^{11,13}$ Nemin tek başına sinterlenmiş zirkonyanın mekanik direncini etkileyen bir faktör olmadığı, ancak yüksek sıcaklığa nem eşlik ettiği zaman faz değişim hızının arttığı bildirilmiştir. ${ }^{13}$ Porselenlerde görülen yorgunluk olayı, zirkonyanın yapısal farklılığı nedeniyle Y-TZP içeren seramiklerde görülmemektedir. Ancak YTZP içeren seramiklerde zamana bağlı olarak gelişen ve tetragonal fazın monoklinik faza geçişinin kontrolsüz bir şekilde artmasıyla kendini gösteren bir yaşlanma olayı söz konusudur. Yaşlanma olayı sonucunda materyalin, yarı stabil özelliğini kaybetmesine bağlı olarak mekanik özellikleri bozulur. ${ }^{14}$

Tüm bu yeni bilgilerin ışığında çalışmamızın ama$\mathrm{Cl}$, hem zirkonyum oksit esaslı alt yapı blokların sinterlenmesi, hem de alt yapı üzerine uygulanacak olan veneer seramiklerin fırınlanması esnasında, özellikle soğuma hızları dikkate alındığında, farklı fırınlama program tercihlerinin, zirkonyum oksit ve veneer seramik arasındaki bağlantıya etkisini araştırmaktır.

Çalışmamızın hipotezi ise, hem zirkonyum oksit örneklerin sinterlenmesinde hem de veneer seramiklerin fırınlanmasında, hızı soğutmanın zirkonyum oksit ile veneer seramik arasındaki bağlantı kuvvetlerini olumsuz etkileyeceği düşünülmektedir.

\section{MATERYAL ve METOD}

İlk olarak elde edilecek zirkonyum oksit alt yapı örnekler ISO TR 11405 spesifikasyonunda belirtildiği gibi, çapı $7 \mathrm{~mm}$. ve kalınlığı $3 \mathrm{~mm}$. olacak şekilde, bilgisayar ortamında çizimlerle, sinterize işlemi sonrası büzülme miktarı da dikkate alınacak şekilde programlanıp CAD/CAM ünitesine (Yena Makine San. ve Tic. Ltd. İstanbul/Türkiye) yüklenerek, 144 adet diskin kazıma işlemleri gerçekleştirilmiştir (Şekil 1). 


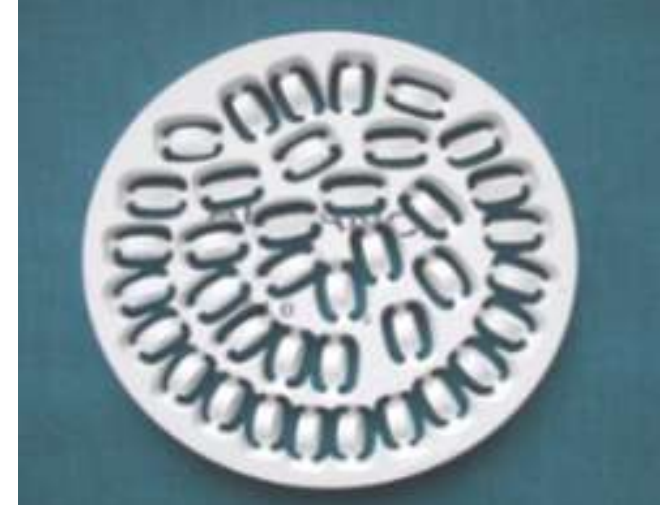

Şekil 1. Çapı 7 mm. ve kalınlığı 3 mm. olarak kazınan diskler

Soğuma hız farkları açısından değerlendirebilmek amacıyla sinterizasyon işlemi için P1 ve P5 olmak üzere iki farklı sinterizasyon programı tercih edilmiştir. Üretici firmanın belirttiği ve sıklıkla sinterizasyon işlemi için tercih edilen P1 programında sıcaklık ilk 2 saat sonunda $1100{ }^{\circ} \mathrm{C}$ ye, 3. saat sonunda $1400{ }^{\circ} \mathrm{C}$ ye ulaşmakta ve takip eden 2 saat boyunca bu sıcaklıkta sabit beklemektedir. Beklenen bu 2 saatin sonunda ise basamaksız olarak doğal soğumaya bırakılmaktadır. Doğal soğuma ise ortalama olarak 5 saat sürmektedir. Sonuç olarak program toplamda ortalama 9 saat sürmektedir (Çizelge 1). P5 programında ise 2 saat sonunda sıcaklık $1100{ }^{\circ} \mathrm{C}$ ye yükselmekte, 3. saatin sonunda sıcaklık $1400{ }^{\circ} \mathrm{C}$ ye ulaşmakta ve takip eden 2 saat boyunca bu sıcaklıkta sabit beklemektedir. Daha sonra her bir saatte sıcaklık $100{ }^{\circ} \mathrm{C}$ düşmekte ve sıcaklık bu şekilde $200{ }^{\circ} \mathrm{C}$ olduğunda doğal soğumaya bırakılmaktadır. Ortalama 1 saat süren doğal soğuma ile beraber P5 programı ortalama 18 saat sürmektedir (Çizelge 2). Daha önce kazınması tamamlanan örneklerden 72 adeti P1 ve 72 adeti P5 programında olmak üzere sinterizasyon fırınında (Protherm Furnaces/ Turkey) ayrı ayrı sinterlenmiştir.

Örnekler sinterlenme işlemi sonrasında 3 dakika ultrasonik olarak (Tecno Gaz Automatic Clean/Italy) temizlenmiş ve sinterlenme işlemi sonrasında örneklerin son boyutları dijital kumpasla ölçülmüştür. Sinterlenmesi tamamlanan zirkonyum oksit esaslı alt yapı örnekler, standart bir yüzey oluşturabilmek için kalem uçlu kumlama cihazıyla (Blastmate II; Ney, Yucaipa, CA), $50 \mu \mathrm{m} \mathrm{Al} \mathrm{O}_{3}$ partikülleri ile 0,4 $\mathrm{MPa}$ basınç altında ve yüzeye $10 \mathrm{~mm}$. uzaklıktan, $15 \mathrm{sn}$. süreyle kumlama işlemine tabi tutulmuş, kumlama sonrası tüm örnekler üç dakika ultrasonik temizleme işlemiyle temizlenmişlerdir.

Daha sonra zirkonyum oksit alt yapılar metal kalıbın içerisine konulup, bu levhanın üzerine veneer porseleni için hazırlanmış ikinci levha yerleştirilip, her alt gruptaki alt yapılar üzerine, ISO/TR 11405 standartlarına uygun olarak, çapı $5 \mathrm{~mm}$ ve yüksekliği $3 \mathrm{~mm}$ olacak şekilde veneer porselen uygulanmıştır (Şekil 23-4). Metal kalıbın vidaları açılarak örnekler kalıptan çıkarılarak veneer porselenler üretici firma talimatlarına uygun olarak, programlanabilen vakumlu porselen fırınında pişirilmeye başlanmıştır.

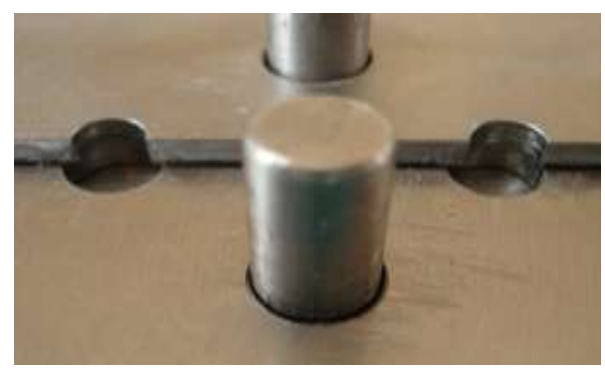

Şekil 2. Veneer seramik uygulamasında kullanılacak olan üst metal kalıp parçası

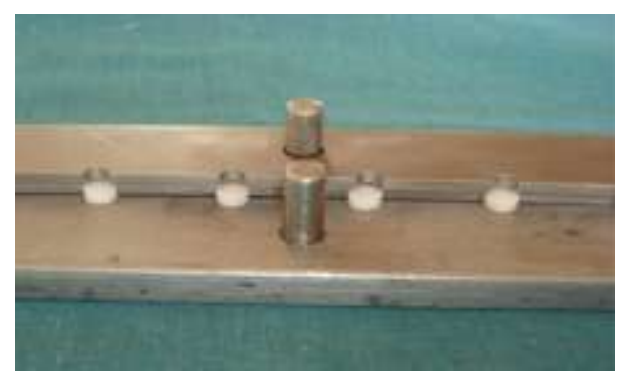

Şekil 3. $\mathrm{ZrO}_{2}$ alt yapının metal kalıba yerleştirilmesi

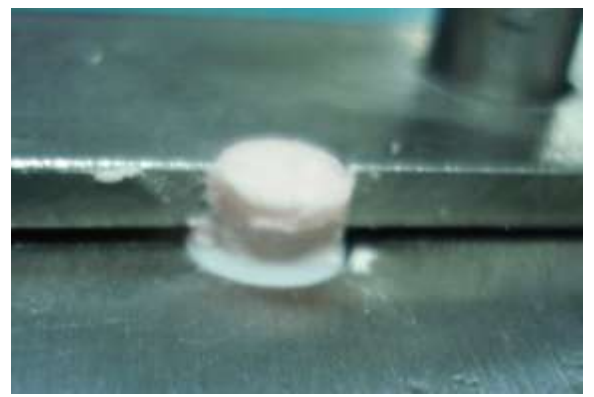

Şekil 4. Üst yapı veneer seramiğin uygulanmış son hali

Noritake - CZR veneer porselen için üretici firmanın önerdiği fırınlama programı, fırın ısısının ön kurutma sıcaklığı olan $600{ }^{\circ} \mathrm{C}^{\prime}$ ye ulaşması ve bu sıcaklıkta 5 dakika bekleme süresinin ardından, her bir dakikada ısı artışı $45{ }^{\circ} \mathrm{C}$ olacak şekilde, fırının maksimum pişirme düzeyi olan 930 0C sıcaklığa çıkması şeklindedir.

Porselen $930{ }^{\circ} \mathrm{C}^{\prime}$ de 1 dakika süreyle kaldıktan sonra iki aşamalı olan (yavaş) soğutma basamağına 
geçilmektedir. İlk aşamada tabla bir miktar aşağı inip bu seviyede 4 dakika bekletildikten sonra ikinci aşamada tamamen aşağı indirilip oda ısısında soğumaya bırakılmaktadır.

Vita VM9 veneer porseleni için üretici firmanın önerdiği fırınlama programı ise, fırın ısısının ön kurutma sıcaklığı olan $500{ }^{\circ} \mathrm{C}^{\prime}$ ye ulaşması ve bu sıcaklıkta 6 dakika bekleme süresini takiben her bir dakikadaki ıSı artışı $55{ }^{\circ} \mathrm{C}$ olacak şekilde maksimum pişirme düzeyi olan $910{ }^{\circ} \mathrm{C}$ sıcaklığa çıkması şeklindedir.

Porselen $910{ }^{\circ} \mathrm{C}$ de 1 dakika süreyle kaldıktan sonra tek aşamalı olan (hızı) soğutma basamağına geçilir ve tabla hiçbir bekleme süresi olmadan tamamen aşağı inerek oda ısısında soğumaya bırakılmaktadır (Şekil 5)

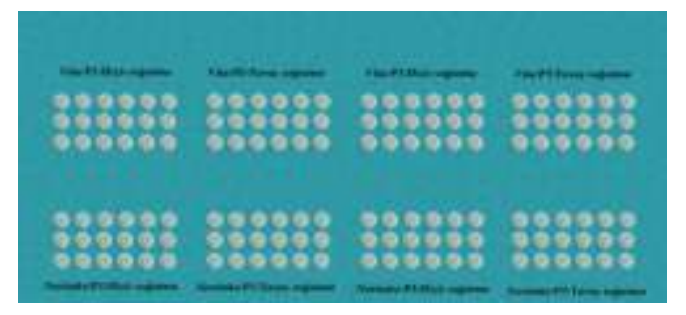

Şekil 5. Sinterlenmesi ve veneerlenmesi bitmiş örneklerin tümü

Farkı fırınlama programları uygulanarak elde edilen örneklerin yarısına termal siklus uygulanmış, diğer yarısına ise herhangi bir işlem uygulanmamıştır. $\mathrm{Bu}$ test, en düşük $5^{\circ} \mathrm{C}$ ve en yüksek $55^{\circ} \mathrm{C}$ aralığında, ortalama $60 \mathrm{sn}$. bekletme süresinde 5.000 devir olacak şekilde termal siklus cihazında (Gökçeler Makine Tic. Ve San. Ltd. Şti. Sivas/Türkiye) gerçekleştirilmiştir.

Test öncesinde örnekler, $37 \pm 1^{\circ} \mathrm{C}^{\prime}$ de 24 saat süreyle distile su banyo cihazında (Nüve BM 302- Nüve Sanayii Malzemeleri İmalat ve Ticaret A.Ş Ankara/Türkiye) bekletilmiştir.

Oluşturulan zirkonyum oksit-seramik örnekler, çapı $14 \mathrm{~mm}$., yüksekliği $12 \mathrm{~mm}$. olan rijit plastik kalıplar içinde akrilik rezinlere gömülerek test düzeneğine yerleştirilmiştir.

Daha sonra örnekler Cumhuriyet Üniversitesi Diş Hekimliği Fakültesi Protetik Diş Tedavisi Araştırma Laboratuvarı'nda, Universal test cihazında (Lloyd instruments LF Plus segensworth Fareham/England) $0,5 \mathrm{~mm} /$ dak. kafa hızında makaslama bağlanma dayanımı testine tabi tutulmuştur. Kesme işlemini yapacak bıçak ucu, ISO TR 11405 spesifikasyonunda belirtildiği şekilde $1 \mathrm{~mm}$. kalınlığında ve ucu künt bir biçimde hazırlanmıştır. Bıçak ucu, örneklerdeki veneer porselen yüzeyiyle $90^{\circ}$ lik bir açı yapacak şekilde yerleştirilmiş, kuvvetler Newton (N) olarak ölçülerek, birim alana düşen yük miktarının saptanabilmesi için, Newton $(\mathrm{N})$ değerleri Megapascal (MPa) değerlerine çevrilmiştir.

İstatistiksel analizler SPSS (Statistical package for Social Sciences, SPSS Inc., Chicago, ABD) bilgisayar paket programının 14.0 versiyonu kullanılarak yapılmıştır. Verilerin değerlendirilmesinde ortalama, standart sapma gibi tanımlayıcı istatistiksel analizler kullanılmışır. Farklı fırınlama uygulamaları sonucu elde edilen bağlanma kuvveti değerlerinin birbirleri ile karşılaştııımasında iki ortalama arasındaki farkın önemlilik testi (Mann Whitney U) kullanılarak istatistiksel analizlerin sonuçları $\mathrm{p}<0.05$ anlamllık düzeyine göre değerlendirilmiştir.

\section{BULGULAR}

Zirkonyum oksit alt yapılar için üretici firmanın belirttiği ve sıkıkla sinterizasyon işleminde tercih edilen P1 programı ve üst yapı veneer porseleni içinse Noritake CZR veneer porseleni için üretici firmanın önerdiği yavaş soğutma (4 dak.) süresini içeren fırınlama uygulaması ile Vita VM9 veneer porseleni için üretici firmanın önerdiği hızlı soğutma (0 dak.) sürecini içeren fırınlama uygulaması bu çalışma grupları için kontrol grubu olarak kabul edilmiştir.

Noritake CZR nin kontrol grubu olan P1+Noritake $\mathrm{CZR}+$ Yavaş soğutma grubunun makaslama bağlanma dayanımı değeri 23,31 MPa iken, P1+Noritake CZR+ Hızlı soğutma grubunun makaslama bağlanma dayanımı 22,55 MPa bulunmuş ve bu değerler arasındaki farkllık istatistiksel olarak anlamllık göstermiştir $(p=0,006)(p<0,05)$.

Vita VM9 veneer porseleninin kontrol grubu olan P1+Vita VM9+Hızlı soğutma grubunun makaslama bağlanma dayanımı değeri 23,66 MPa iken, P1+Vita VM9+Yavaş soğutma grubunun makaslama bağlanma değeri 24,26 MPa bulunmuş ve bu değerler istatistiksel olarak anlamlılık göstermemiştir $(p=0,122)$ $(p>0,05)$.

Yavaş soğutma sürecini içeren fırınlama uygulamasının, P1 programında sinterlenmiş alt yapı üzerine uygulanmış veneer porselen gruplarının makaslama bağlanma dayanımına olası etkileri karşılaştıııdığında $\mathrm{P} 1+$ Noritake $\mathrm{CZR}+$ Yavaş soğutma (kontrol) grubuna ait değerin 23,31 MPa, P1+Vita VM9+Yavaş soğutma grubuna ait değerin ise $24,26 \mathrm{MPa}$ olduğu görülmüştür. Bu gruplar arasındaki farkllık istatistiksel olarak anlamllıı göstermiştir $(p=0,006) \quad(p<0,05)$. P1+Vita 
VM9+Hızlı soğutma (kontrol) grubu ile, P1+Noritake CZR+Hızlı Soğutma gruplarına ait bağlanma dayanımı değerleri ise sırasıyla 23,66 MPa ve 22,55 MPa olarak bulunmuştur. Yine bu gruplar arasındaki farklılık da istatistiksel yönden anlamlı bulunmuştur $(p=0,004)$ $(p<0,05)$.

Zirkonyum oksit alt yapıların sinterlenmesi sürecinde farklı sinterleme süre tercihlerinin alt yapı ile veneer porseleni arasındaki bağlanma dayanımı üzerine olası etkilerini değerlendirmek amacıyla P1 ve P5 programında sinterizasyonu gerçekleştirilmiş olan gruplar birbirleriyle karşılaştırıldığında $\mathrm{P} 1+$ Noritake $\mathrm{CZR}+$ Yavaş soğutma (kontrol) grubunun 23,31 MPa, P5+Noritake CZR+Yavaş soğutma grubunun ise 24,34 MPa değer sergilediği görülmüştür. Bu gruplar arasındaki farklılık istatistiksel yönden anlamlılık göstermiştir $(p=0,001) \quad(p<0,05)$. P1+Vita VM9+Hızlı soğutma (kontrol) grubu ile, P5+Vita VM9+Hızlı soğutma gruplarına ait bağlanma dayanımı değerleri ise sırasıyla 23,66 MPa ve 25,12MPa olarak bulunmuş olup yine bu gruplar arasındaki farklılık da istatistiksel yönden anlamlı bulunmuştur $(p=0,009)(P<0,05)$, (Tablo 1-2)

Tablo 1. P1 sinterleme grubunda Vita VM9 ve Noritake CZR veneer porselenlerinin TS öncesi ve sonrası bağlanma dayanımı değerleri

\begin{tabular}{|c|c|c|c|c|}
\hline $\begin{array}{c}\text { Sinterleme } \\
\text { Programı }\end{array}$ & $\begin{array}{c}\text { Üst Yapı } \\
\text { Veneer } \\
\text { Porselen }\end{array}$ & $\begin{array}{c}\text { Veneer Porselen } \\
\text { Soğutma } \\
\text { Prosedürü } \\
\end{array}$ & $\begin{array}{c}\text { Termal } \\
\text { Siklus }\end{array}$ & $\begin{array}{c}\text { Ortalama } \\
\text { Değer } \\
(\mathrm{MPa})\end{array}$ \\
\hline \multirow{8}{*}{$\mathbf{P}_{\mathbf{1}}$} & \multirow{4}{*}{ Vita VM9 } & Hızlı (0 dak.) & Yok & $23,66 \pm 0,73$ \\
\hline & & Hızı ı (0 dak.) & Var & $20,80 \pm 0,73$ \\
\hline & & Yavaş (4 dak.) & Yok & $24,26 \pm 0,56$ \\
\hline & & Yavas (4 dak.) & Var & $21,47 \pm 0,73$ \\
\hline & \multirow{4}{*}{$\begin{array}{c}\text { Noritake } \\
\text { CZR }\end{array}$} & Hızlı (0 dak.) & Yok & $22,55 \pm 0,46$ \\
\hline & & Hızılı (0 dak.) & Var & $19,75 \pm 0,80$ \\
\hline & & Yavaş (4 dak.) & Yok & $23,31 \pm 0,53$ \\
\hline & & Yavaş (4 dak.) & Var & $20,94 \pm 0,77$ \\
\hline
\end{tabular}

Tablo 2. P5 sinterleme grubunda Vita VM9 ve Noritake CZR veneer porselenlerinin TS öncesi ve sonrası bağlanma dayanımı değerleri

\begin{tabular}{|c|c|c|c|c|}
\hline $\begin{array}{l}\text { Sinterleme } \\
\text { Programı }\end{array}$ & $\begin{array}{l}\text { Üst Yapı } \\
\text { Veneer } \\
\text { Porselen }\end{array}$ & $\begin{array}{l}\text { Veneer Porselen } \\
\text { Soğutma } \\
\text { Prosedürü }\end{array}$ & $\begin{array}{l}\text { Termal } \\
\text { Siklus }\end{array}$ & $\begin{array}{l}\text { Ortalama } \\
\text { Değer } \\
\text { (MPa) }\end{array}$ \\
\hline \multirow{8}{*}{$\mathbf{P}_{5}$} & \multirow{4}{*}{ Vita VM9 } & Hızlı (0 dak.) & Yok & $25,12 \pm 0,99$ \\
\hline & & Hızıı (0 dak.) & Var & $22,12 \pm 0,80$ \\
\hline & & Yavaş (4 dak.) & Yok & $25,57 \pm 0,64$ \\
\hline & & Yavaş (4 dak.) & Var & $22,39 \pm 0,80$ \\
\hline & \multirow{4}{*}{$\begin{array}{l}\text { Noritake } \\
\text { CZR }\end{array}$} & Hızlı (0 dak.) & Yok & $23,80 \pm 0,54$ \\
\hline & & Hızlı (0 dak.) & Var & $20,89 \pm 0,53$ \\
\hline & & Yavaş (4 dak.) & Yok & $24,34 \pm 0,37$ \\
\hline & & Yavaş (4 dak.) & Var & $21,89 \pm 0,58$ \\
\hline
\end{tabular}

\section{TARTIŞMA}

Zirkonyum oksit alt yapılı tam seramik sistemlerinde materyale bağlı olarak gelişen komplikasyonların, metal destekli porselen restorasyonlardan fazla olduğu bilinmektedir. ${ }^{15}$ Sailer ve ark., 45 hastaya posterior bölgede 3 ile 5 üyeli zirkonyum oksit alt yapılı sabit bölümlü protez uygulamış, protezlerin 3 yıllık takibinin ardından yaptıkları değerlendirmede üst yapı porseleninin alt yapıdan ayrılma başarısızlığını \%13 olarak tespit etmişlerdir. ${ }^{16}$ Piconi ve ark. benzer başka bir çalışmada ise DC-Zirkonyum oksit esaslı restorasyonların 2 yıl sonundaki veneer kırılma oranlarını \% 15 tespit etmişlerdir. ${ }^{14}$ Bu oranlar metal seramik restorasyonlara nazaran oldukça yüksektir. Metal seramik restorasyonlarda 3 yıl sonunda veneer tabakasının kırılmasına bağlı gelişen başarısızlık oranları, tek kuronlar için \% 0,4 ve köprüler için \% 2,9 olarak bildirilmiştir. ${ }^{17-19}$

Seramikler baskı streslerine karşı dayanıklıdırlar ve küçük baskı stresleri istenilen bir durumdur. Aboushelib ve ark. yaptıkları bir çalışmada, termal genleşme katsayısı 12,5 x 10-6/C olan deneysel bir üst yapı porselenini, termal genleşme katsayısı 10,5 x 10$6 / C$ olan zirkonyum oksit alt yapı üzerine uygulamışlar ve veneer porseleninde spontan kırıklar belirlemişlerdir. Termal genleşme katsayısı 9,5 x 10-6/C olan başka bir veneer porselenini aynı zirkonyum oksit alt yapı üzerine uyguladıklarında ise daha iyi sonuçlar elde etmişlerdir. ${ }^{20,21}$ Guazzato ve ark., IPS Empress altyapı materyali ile dokuz farklı dentin porseleninin ISIsal uyumluluklarını inceledikleri çalışmalarında, dilatometre analizi ile bu materyallerin her birinin ısısal genleşme katsayılarını tespit etmişlerdir. Birinci fırınlamadan sonra, altyapı ve dentin porseleninin Isısal genleşme katsayıları farkı 1 x 10-6/C'den daha az olan kronlarda çatlak gözlenmemiştir. Bu farkın $1.5-1.6$ x $10-6 / C$ olduğu kronlarda ise en az bir çatlak tespit edildiği bildirilmiştir . ${ }^{22}$ Saito ve ark. tek çeşit Y-TZP alt yapı (Katana Zirconia) ile 5 değişik üst yapı porseleni (Noritake CZR, CerconCeramkiss, IPS e-maxCeram, Vintage ZR, VitaVM9) arasındaki kesme bağlanma dayanımlarını değerlendirdikleri çalışmada bağlanma dayanım değerlerini; Noritake CZR grubu için 27,0 MPa, Vita VM9 grubu için 30,9 MPa, Cercon Ceramkiss grubu için 22,0 MPa, IPS e- maxCeram grubu için 22,1 MPa ve Vintage ZR grubu içinse 24,8 MPa bulmuşlardır. Farklı üst yapı porselenleri arasında çıkan bu değerler istatistiksel olarak anlamlı bulunmuştur. Çıkan bu sonuçların ise zirkonyum oksit alt yapı ile veneer porseleni arasındaki termal genleşme katsayısı farkından dolayı olduğu vurgulanmıştır. ${ }^{23}$ Çalışmamızda kulIanılan Noritake CZR ve Vita VM9 veneer porselenlerinin zirkonyum oksit alt yapılara bağlanma dayanımları incelendiğinde, her iki veneer porseleni için üretici firma tavsiyeli prosedürler uygulanan örneklerden; kontrol grubunda Vita VM9 veneer porseleni için 23,66 
MPa, Noritake CZR için 23,31 Mpa bağlanma kuvveti değerleri elde edilmiştir. Veneer porselenlerin bağlanma dayanımları arasındaki bu fark istatistiksel olarak anlamlı bulunmuştur ve bu farkın, kullanılan veneer porselenlerin sahip olduğu farklı termal genleşme katsayılarından kaynaklandığı düşünülmektedir.

Tan ve ark. Lava all seramik alt yapı ile Vita VM9 veneer porseleni arasındaki bağlanma dayanımı üzerine yaptığı çalışmasında, veneer porselenin fıınlanması sürecinde üç farklı ısıtma hızı ve üç farkı soğutma seçeneklerinin etkilerini değerlendirmişler ve soğutma prosedürünün Isıtma prosedürüne göre bağlanma dayanımı üzerine etkisinin daha belirgin olduğunu bildirmişlerdir. Hızl, normal ve yavaş olarak adlandırdıkları soğutma seçenekleri içerisinde en yüksek bağlantı değerini yavaş soğutma grubunda elde etmişlerdir. ${ }^{24}$

Komine ve ark. yaptıkları bir çalışmada tek bir zirkonyum oksit alt yapıya (Noritake, Katana) 2 farkı veneer porselenini (Cerabien ZR, IPS e.maxCeram), üretici firmaların belirttiği prosedürde pişirip; hızlı ( 0 dak.) ve yavaş (4 dak.) soğutma işleminin kesme bağlanma dayanımlarına etkisini incelemişlerdir. Yapılan incelemeler sonucunda yavaş ve hızı soğutulan Noritake CZR örnekler arasında bağlanma dayanımı farkı anlamsız ( $p=0,382, p>0,001)$ olmakla beraber yavaş soğutmada hızlı soğutmaya göre bağlanma değerleri daha yüksek çıkmışıı. Bununla beraber IPS e.max Ceram grubunda bağlanma değerleri farkı hızlı ve yavaş soğutmada anlamlı çıkmış ve yine Noritake CZR grubunda olduğu gibi yavaş soğutma grubundaki makaslama bağlanma dayanım değeri daha yüksek bulunmuştur $(p<0,001) .{ }^{25}$

Çalışmamızda, P1 ve P5 ana gruplarında, hem Noritake CZR, hem de Vita VM9 alt gruplarını, hızlı ve yavaş soğutulan örnekleri arasında, yavaş soğutulan örneklerin makaslama bağlanma dayanımları hem yüksek çıkmış hem de istatistiksel fark anlamlı bulunmuştur. Bu bulgular göze alınarak Komine ve ark. ile örtüşecek şekilde yavaş soğutmanın bağlanma dayanım değerlerini artırdığı tespit edilmiştir.

Tüm veriler değerlendirildiğinde, çalışmamızın hipotezinde belirttiğimiz gibi her iki ana grubumuz olan P1 ve P5 gruplarında tüm bağlanma kuvvetleri göz önüne alındığında, hızlı soğutma prosedürü uygulanan bağlanma kuvvetleri değerlerinin daha düşük çıktıkları görülmüş olup, hipotezimizi destekleyen veriler elde edilmiştir.

\section{SONUÇ}

Yapılan bu in vitro çalışmada, 'Zirkonyum oksit ve Veneer Seramik Arasındaki Bağlantıya Farklı Fırınlama Uygulamalarının Etkisi' karşılaştırmalı olarak incelenmiş, aşağıdaki sonuçlar elde edilmiş̧ir:

1. P1 (Hızlı) ve P5 (Yavaş) olmak üzere sinterlenen zirkonyum oksit alt yapıların bağlanma değerleri karşılaştıııldığında P5 ana grubundaki bağlanma dayanımı değerleri, P1 grubundakilere göre daha yüksek bulunmuştur.

2. Zirkonyum oksit esaslı alt yapı malzemeleri üzerine uygulanan Vita VM9 veneer porseleni ile Noritake CZR veneer porseleninin bağlanma dayanımı değerleri istatistiksel olarak farkllık $(p<0,001)$ göstermektedir. En yüksek bağlanma dayanımı değerleri 25,57 MPa ile Vita VM9 veneer porseleninde, en düşük bağlanma dayanımı değerleri ise $19,75 \mathrm{MPa}$ ile Noritake CZR veneer porseleninde elde edilmiştir.

3. Zirkonyum oksit esaslı alt yapılar üzerine hızı ve yavaş prosedürde uygulanan veneer seramiklerin bağlanma dayanımları karşılaştııılığında bütün gruplarda yavaş soğutulan örneklerin bağlanma dayanımı değerleri hızı soğutulan gruplara göre yüksek çıkmış, sonuçlar istatistiksel olarak değerlendirildiğinde bazı gruplarda elde edilen değerler anlamlı, bazılarında ise anlamsız bulunmuştur.

4. Termal siklus uygulamasının bağlanma dayanımı üzerine etkisinin olumsuz olduğu belirlenmiştir.

5. Tüm örnekler mikroskopik olarak incelendiğinde; kombine kopma sayısının (90), adeziv kopma sayısından (52) daha fazla olduğu tespit edilmiş, sadece 2 örnekte koheziv kopma gözlenmiş̧ir.

6. Zirkonyum oksit alt yapı ile veneer porseleni arasındaki bağlantı mekanizmasına açıklık getirecek yeni çalışmalara intiyaç duyulmaktadır.

NOT: Bu makale yazarlarından hiçbirinin makalede bahsi geçen konu veya malzemeyle ilgili herhangi bir iliskisi, bağlantısı veya parasal çıkar durumu söz konusu değildir.

\section{KAYNAKLAR}

1. Anusavice $\mathrm{KJ}$. Recent developements in restorative dental ceramics. J Am Dent Assoc 1993; 124:72-84.

2. McLean JW. Dental Ceramics. Proceeding of the first International symposium on ceramics. Chicago: Quintessence Pub Co 1983; 20:13-40. 
3. Ozdemir H, Bayındır F. Effect of different surface treatment on bond strength of resin cement to zirconium and leucite-reinforced glass ceramic. J Dent Fac Atatürk Uni 2018; 28: 150-6.

4. Anusavice KJ. Recent developements in restorative dental ceramics. J Am Dent Assoc 1993; 124:72-84.

5. Nayır E., Diş hekimliği maddeler bilgisi.(John McCabe), 1993; 7 .

6. Lang LA, Wang RF, Kang B, White SN. Validation of finite element analysis in dental ceramics research. J Prosthet Dent 2001; 86: 650-4.

7. Raigrodski AJ. Contemporary all-ceramic fixed partial dentures: a review. Dent. Clin. North Am 2004; 48:531-44.

8. Piconi C, Maccauro G. Zirconia as a ceramic biomaterial. Biomaterials 2004; 20:1-25.

9. Conrad HJ, Seong WJ, Pesun IJ. Current ceramic materials and systems with clinical recommendations: a systematic review. J Prosthet Dent 2007; 98:389-404.

10. Kelly JR. Dental ceramics: current thinking and trends. Dent Clin N Am 2004; 48:513- 30.

11. Denry I, Kelly JR. State of the art of zirconia for dental applications. Dent Mater 2008; 24: 299307.

12. Guazzato M, Albakry M, Ringer SP, Swain MV. Strength, fracture toughness and microstructure of a selection of all-ceramic materials. Part I. Pressable and alumina glass-infiltrated ceramics. Dent Mater 2004; 20:441-8.

13. Saldana JM, Ramirez $H$, Vigueras DJ, Iga T. Mechanical properties and lowtemperature aging of tetragonal zirconia polycrystals processed by hot isostatic pressing. J Mater Res 2003; 63;18.

14. Piconi C, Maccauro G. Zirconia as a ceramic biomaterial. Biomaterials 1999; 20:1-25.

15. Ghazy MH, Madina MM, Aboushelib MN. Influence of fabrication techniques and artificial aging on the fracture resistance of different cantilever zirconia fixed dental protheses. J Adh Dent 2011; 10:56-63.

16. Sailer I, Feher A, Filser F et al. Prospective clinical study of zirconia posterior fixed partial dentures: 3-year follow-up. Quintessence Int 2006; 37: 685-93.

17. Jones DW. The stregth and stregthening mechanism of dental ceramics. Dental Ceramics. Proceedings of the first international symposium on ceramics. Chicago, Quintessence 1983; 83141.
18. Xiao-ping $L$, Jie-mo $T$, Yun-long $Z$, Ling $W$. Strength and fracture toughness of $\mathrm{MgO}$ modified glass infiltrated alumina for CAD/CAM. Dent Mater 2002; 18:216-20.

19. Pjetursson BE, Sailer I, Zwahlen M, Hammerle CHF. A systematic review of the survival and complication rates of all-ceramic and metalceramic reconstructions after an observation period of at least 3 years. Part II: fixed partial dentures. Clin Oral Imp Res 2007; 18:86-96.

20. Aboushelib MN, de Jager N, Kleverlaan CJ, Feilzer AJ. Microtensile bond strength of different components of core veneered all-ceramic restorations. Dent Mater 2005; 21: 984-91.

21. Aboushelib MN, Kleverlaan CJ, Feilzer AJ. Effect of zirconia type on its bond strength with different veneer ceramics. J Prosthodont 2008; 17:401-8.

22. Guazzato M, Albakry M, Swain MV, Ironside J. Mechanical properties of in- ceram alumina and in-ceram zirconia. Int J Prosthodont 2002; 15: 339-46.

23. Saito A, Komine F, Blatz MB, Matsumura H. A comparison of bond strength of layered veneering porcelains to zirconia and metal. J Prosthet Dent 2010; 104:247-257.

24. Tan JP, Sederstrom D, Polansky JR, McLaren EA, White SN. The use of slow heating and slow cooling regimens to strengthen porcelain fused to zirconia. J Prosthet Dent 2012: 107; 163-9.

25. Komine F, Saito A, Kobayashi K, Koizuka M, Koizumi $H$, Matsumura $H$. Effect of cooling rate on shear bond strenght of veneering porcelain to a zirconia ceramic material. J Oral Sci 2010; 52:647-52.

\author{
Sorumlu Yazarın Yazışma Adresi \\ Türker AKAR, DDS, PhD \\ Assistant Professor \\ Erzincan University Faculty of Dentistry \\ Department of Prosthodontics \\ Erzincan, Turkey \\ e-mail: turkerakar24@gmail.com
}

